\title{
Spotlighting shared goals for science education and communication
}

Book

Reviewed by

Abstract

Keywords
MaArten C.A. van der Sanden and Marc J. VRies (2016). Science and TECHNOLOGY EDUCATION AND COMMUNICATION: SEEKING SYNERGY. Sense Publishers: RotTerdam, Netherlands.

\section{Laura Fogg-Rogers}

van den Sanden and Vries curate reflections and insights about the shared goals, practices and processes which bring together academics and practitioners in science education and communication. The book spotlights areas of productive overlap but is just the beginning for meaningful collaboration.

Public engagement with science and technology; Science communication: theory and models, Science education

On the face of it, science teachers and science communicators would appear to operate in two different worlds; that of science and technology education (STE) and science and technology communication (STC). Both fields have formed via different historical routes, and operate in distinct academic, social and communication environs. However, the aim of this book is to demonstrate to practitioners and academics that we have more in common than we think. As the editors state, 'Part of what educators do is communicating and part of what communicators do is educating' [p. 4].

The book aims to build bridges between these fields by seeking synergy; highlighting values, concepts and processes where we have much to learn from each other. The editors state that they initially set forth a challenge to the authors [p. vii], that through collaboration between educators and communicators they would develop coherent chapters to expand thinking in each domain. This process did not go to plan, and instead the flow of the book indicates that whilst good intentions may be there, like all relationships, collaboration can be difficult to achieve.

The book begins with a metaphorical bicycle ride into the virtual, a twisting and turning mind-expanding insight into the serendipity of invention by John Dakers. While the chapter is interesting as an insight into how the process of science and technology is (or rather isn't) communicated in education and the media, it does prove to be a challenging read. The pragmatic practitioner within me would have 
rather started with the more tangible concepts of shared goals and practices; in this case an understanding of how each field interacts with their audiences.

This is provided by Anne-Lotte Masson, Jenni Metcalfe and Patricia Osseweijer in the chapter on 'Motivating Engagement' mid-way through the book. The chapter provides definitions, contexts and examples from each field about what engagement means, how it is enacted, and the ultimate intended outcomes. They state that "In science communication, engagement may have a number of desired outcomes depending on the objectives, but in science education, engagement is supposed to lead to successful uptake of knowledge and interest in science" [p. 50]. The rundown is so thorough that this chapter could provide a set text for courses in both STE and STC. It concludes with a challenge for practitioners, that in working towards inquiry-based learning in STE, and towards participation in STC, both fields would be stronger together.

Merryn McKinnon and Judith Vos concur in their chapter about 'Crossing a Threshold'. They argue that, "Irrespective of the label, both science educators and science communicators have the same fundamental goal - to engage their audience... However both fields seem to be pursuing this aim in isolation from the other, when a more collaborative approach could yield far greater benefits" [p. 27]. It's a challenge that Emma Weitkamp and Dawn Arnold appear to have taken up in their case study chapter on "Exploring the impacts of embedding science communication principles in a collaborative learning space". It can only be hoped that more such projects develop these shared goals to enrich both STE and STC, and the experiences of both students and audiences.

The second half of the book moves away from the goals of each field towards looking at the processes for how this can happen. Again, a chapter in the middle of the section might have provided a more logical place with which to start the exposition; here Steven Flipse and Durdane Bayram-Jacobs examine how the concept of Responsible Research and Innovation (RRI) is bridging science education and communication. They appear to be the only authors to have read the work of their book compatriots, and as such, the chapter provides a coherent synopsis of both the topic and of how the work of their fellow authors relate. They argue that the red thread throughout the book is that 'Concepts that are relevant for education and communication have value across and between the two related disciplines" [p. 147].

Ideas for conceptual practice are described in two of the preceding chapters. Nick Verouden explores the 'Significance of Silence' in communication and social learning, arguing that listening to the times when people (professionals, students or audiences) are not speaking can be just as powerful as listening to what they are saying, allowing practitioners to identify power, cooperation and the health of relationships. Caroline Wehrmann and Ineke Henze-Rietveld describe the process of establishing a shared STE and STC Masters course at Delft University; with the overlap being the development and reflective practice of the practitioner. This chapter provides many learnings from STE which would be highly applicable during this time of increased calls for the professionalization of STC. 
The need to expand and reinvent practice is explored in the chapter by the editors themselves, with their argument that Design Thinking — a process of innovation and constant review - provides a critical linking point between the two fields. The concept is exemplified through the case study provided by Durdane Bayram-Jacobs about the EU Engage project. This final chapter details efforts by STC practitioners to develop RRI materials about current science and technology examples which will be adopted, adapted and finally transformed by STE practitioners. She argues that the development of educational materials and innovation processes are useful areas where practitioners can share their subject knowledge.

My logical endpoint would instead be the chapter by Ayelet Baram-Tsabari and Bruce Lewenstein, which considers assessment of outcomes from STE or STC. They argue that traditionally, while STE has focussed on conceptual learning and STC has focussed on satisfaction and excitement, both have been more concerned with their audiences. They instead explore "what scientists take away from interaction with public communication of science" with insights for "issues that need to be considered in all education-inflected assessments of public communication of science and technology" [p. 163]. They indicate that impacts will be felt in several learning strands; affective aspects, knowledge, approaches, reflection, participation, and identity.

The book clearly shines several spotlights on highly relevant areas for developing theory and practice in both STE and STC. However, the chapters are sometimes disjointed and unconnected, leaving the reader feeling like they are spotlighting many aspects of connection without ever fully seeing a true picture. The editors may have felt this themselves, as they state that "this book is no more than a beginning" [p. viii]. To this end, it is very effective and insightful.

Laura Fogg-Rogers is a Senior Research Fellow in Science Communication at the University of the West of England, Bristol. Her research brings together engagement, involvement and learning through evaluating outreach and communication interventions, as well as teaching on the MSc in Science Communication. E-mail: laura.foggrogers@uwe.ac.uk.

\section{How to cite}

Fogg-Rogers, L. (2017). 'Spotlighting shared goals for science education and communication'. JCOM 16 (01), R03. 